\title{
Southern Hemisphere Atmosphere Wavenumber 4 driven Marine Heat Waves and Marine Cool Spells
}

Stephen Chiswell ( $\nabla$ s.chiswell@niwa.cri.nz)

National Institute of Water and Atmospheric Research https://orcid.org/0000-0002-5957-3706

\section{Article}

Keywords: Marine Heat Waves, Marine Cool Spells, Global Teleconnections, Southern Hemisphere

Posted Date: April 5th, 2021

DOI: https://doi.org/10.21203/rs.3.rs-352621/v1

License: (c) (i) This work is licensed under a Creative Commons Attribution 4.0 International License. Read Full License

Version of Record: A version of this preprint was published at Nature Communications on August 6th, 2021. See the published version at https://doi.org/10.1038/s41467-021-25160-y. 
10 Stephen M. Chiswell ${ }^{1}$, and Marine Cool Spells

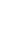

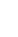
(n) 2 6

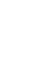
8

\section{ORCID} 1

\section{Southern Hemisphere Atmosphere Wavenumber 4 driven Marine Heat Waves}

${ }^{1}$ National Institute of Water and Atmospheric Research, Private Bag 14-901,

4 Wellington, New Zealand

Corresponding author: Stephen Chiswell s.chiswell@,niwa.cri.nz

- Stephen M. Chiswell https://orcid.org/0000-0002-5957-3706 
Abstract

When SST anomalies are defined with respect to a changing baseline and

24 normalised by their $90^{\text {th }}$ percentile, the Tasman Sea is one of the southern hemisphere

25 hotspots of marine heat waves (MHW) and marine cool spells (MCS). There is little

26 evidence that MHW or MCS are increasing in either frequency or intensity, although

27 the duration of MHW has increased from $8 \mathrm{~d}$ four decades ago to $26 \mathrm{~d}$ now.

28 On average, Tasman Sea MHW/MCS co-occur with MHW/MCS in the

29 Atlantic, Indian, and eastern-Pacific Oceans, in a wavenumber 4 (W4) pattern.

30 Canonical MHW and MCS show they are likely driven by a stalling of the eastward

31 propagation of a W4 atmospheric wave. During MHW, this slow down leads to near-

32 stationary anomalously high and low air pressure areas driving anomalous north-

33 easterly winds over the Tasman Sea. During MCS, similar a slow-down occurs, but

34 shifted by one-half wavelength zonally.

36 Keywords

37 Marine Heat Waves, Marine Cool Spells, Global Teleconnections, Southern

38 Hemisphere 


\section{Introduction}

Not only has the trend in sea surface temperature (SST) been towards warmer oceans over the last few decades (e.g. Roemmich et al., 2012), and even may be accelerating (Bâki Iz, 2018), but it has also been suggested that marine heat waves (MHWs) have become stronger and or more frequent over the last century (Oliver et al., 2018). MHW are sometimes considered as good analogues for possible future oceans (Salinger et al., 2019), and are often associated with detrimental impact on ocean primary production, for example, extreme MHW have been associated with a loss of kelp forests in Western Australia (Wernberg et al., 2016), a massive mortality of sea birds in the NE Pacific (Jones et al., 2018), and a collapse of the salmon fishing industry around New Zealand. (Hulburt, 2018).

A recent review of MHW (Oliver et al., 2021) shows that despite considerable interest and research into them, there are still many unanswered questions, for example, whether they are locally or distantly forced, what the relative roles of atmospheric and oceanic forcing are, and the degree of similarity between different MHW. Some research has suggested that MHW are driven by different mechanisms, for example, Holbrook et al. (2019) showed a variety of forcing mechanisms led to a heterogeneous distribution of occurrence and duration around the globe. In contrast, Sen Gupta et al. (2020) suggested that globally, almost all extreme MHWs are associated with suppressed wind speeds during their build up phase. In some, but not all, cases this was also related to suppressed turbulent heat losses from the ocean (in particular, latent heat). Supporting this, Bond et al. (2015) suggested MHW in the north-east Pacific Ocean were primarily driven by much higher than normal air pressure.

In the southern hemisphere, there have been a variety of proposed mechanisms for MHW. Behrens et al. (2019) suggested that heat content fluctuations in the Tasman Sea are predominately controlled by variations in the meridional heat transport from the subtropics via the East Australian Current, impacted by wind stress curl anomalies north of the region. Li et al. (2020) similarly suggested about half of historical Tasman Sea MHWs were due to increased poleward transport within the East Australian Current, but that the variability is driven by westward-propagating sea surface height anomalies from the interior South Pacific. There are also questions about how deep MHW penetrate, whether they are simply due to a lack of wind stress 
72 leading to surface-intensified warming (Salinger et al., 2019), or whether they can show deep expression with maximum warming below the surface as seen off Western Australia (Schaeffer \& Roughan, 2017).

Recently, there has been a suggestion that southern-hemisphere SST variability is globally interconnected. Senapati et al. (2021) revealed the presence of a stationary zonal wavenumber 4 (W4) pattern in SST anomaly in the southern subtropics $\left(20^{\circ} \mathrm{S}-\right.$ $55^{\circ} \mathrm{S}$ ) that is seasonally phase-locked to the austral summer, and persists up to midautumn (i.e., when MHW are most common). They suggested that thermodynamic coupling of the atmosphere and the upper ocean helps in generating the W4 pattern, and that the W4 pattern in SST is independent of other natural variability such as Southern Annular Mode, and Indian Ocean Dipole or El Niño/Southern Oscillation.

While MHW have gathered considerable scientific attention, their cool counterparts, marine cool spells (MCS) have attracted much less interest, even though MCS may also impact primary production. For example, Chiswell and O'Callaghan (2021) showed that at least near the coast, cool spells can have a positive influence in production, likely due to upwelling, but it is not so clear if they also have an impact in the open ocean.

In this article, we use global satellite-derived reanalyses of sea surface temperature, sea-level air pressure, air-sea heat flux, and wind stress to investigate whether MHW/MCS in the southern hemisphere are becoming more frequent or more intense, and their relationship to global forcing.

In a warming ocean, if temperature anomalies were defined relative to a constant baseline value, there would be a trend towards more MHW and fewer MCS, so that eventually, the ocean would be in a continuous state of MHW. It is likely that the mechanisms forcing MHW/MCS are not the same as those driving long-term warming, and so it is important to separate MHW/MCS from any global warming. Thus, we define temperature anomalies with respect to the 1982-2020 trend. When SST anomalies are normalised by their $90^{\text {th }}$ percentile to take into account local variability, the Tasman Sea is one of the southern hemisphere hotspots of MHW, and this article focusses on this region. About $20 \mathrm{MHW}$ and MCS occurred in the Tasman Sea between 1982 and 2020. We show that on average, these events co-occur with corresponding events in the Atlantic, Indian, and eastern-Pacific Oceans, in a W4 
104 structure. 'Canonical' MHW and MCS constructed from these events show these events are likely driven by a stalling of a W4 atmospheric wave.

\section{Results}

The southern hemisphere SST 1982-2020 trend (Figure 1a) is consistent with trends for similar periods published elsewhere (e.g. Bulgin et al., 2020; Sutton \& Bowen, 2019). Highest warming occurred off south-eastern Australia, South America, South Africa, and in the central South Pacific Ocean. In these areas, the trend reached $0.3^{\circ} \mathrm{C}$ decade $^{-1}$. Cooling occurred in the east Pacific Ocean near $20^{\circ} \mathrm{S}$, and in the Southern Ocean, with maximum cooling about $0.3^{\circ} \mathrm{C}$ decade ${ }^{-1}$ south-east of South

113 America.

Once the trend and annual cycles are removed, the $90^{\text {th }}$ percentile of SST anomalies from $1982-2020$ was typically $0.75^{\circ} \mathrm{C}$ to $1^{\circ} \mathrm{C}$ over most of the Southern Hemisphere, with highest values along the Pacific Ocean equator, along a zonal band south of Africa associated with the Agulhas Current retroflection (Lutjeharms \& Van Ballegooyen, 1988), and east of South America associated with the BrazilFalklands/Malvinas Confluence (Gordon, 1989) (Figure 1b). The number of days when the SST anomaly normalised by this $90^{\text {th }}$ percentile, $\mathrm{SST}_{\mathrm{A}}$, exceeded 3 during 1982-2010 (i.e. exceeding the category 3 MHW criterion of Hobday et al., 2018), shows high values near the equator (presumably reflecting El Nino events), in the central southern Pacific Ocean, and in the eastern Tasman Sea, where $\mathrm{SST}_{\mathrm{A}}$ exceeded 3 for more than 25 days (Figure 1c).

Based on (Figure 1c), and given the existing usage of the Tasman Box by other researchers, we computed the normalised SST anomaly averaged over this box, $\mathrm{SST}_{\mathrm{Tas}}$, as an index of MHW activity in the Tasman Sea. This index ranged from -2.1 to 2.7 (Figure 2), with 22 warm events where $\mathrm{SST}_{\text {Tas }}$ exceeded 1.0 for at least $5 \mathrm{~d}$, and 21 cool events where $\mathrm{SST}_{\text {Tas }}$ was less than -1.0 for at least $5 \mathrm{~d}$. Many of these warm events correspond to documented MHW, but because the index is averaged over the Tasman Box, the intensities of individual warm events do not necessarily correspond to intensities of individual MHW. For example, the extreme MHW in 2015/16 seen mostly in the western Tasman Sea (Oliver et al., 2017) appears only as a moderate event in our index. However, the three most extreme warm events in our index correspond to well documented MHW - in February 1998 (Li et al., 2020), 
136 December 2017 (discussed extensively in Salinger et al., 2019), and January 2019

137 (Chiswell \& O'Callaghan, 2021), with a combined average $\mathrm{SST}_{\text {Tas }}$ of 2.23. The three strongest cool events were in January 2005, January 2007 and November 2012, with a combined average $\mathrm{SST}_{\mathrm{Tas}}$ of -1.8 .

Linear regressions show no statistically significant change in intensity of warm events, $\left(r^{2}=0.12, p=0.1\right)$, although there is a significant increase in the intensity of cold events (slope $=-0.15$ /decade, $\mathrm{r}^{2}=0.38, \mathrm{p}=0.003$ ) driven by the cluster of weak cool events in the mid-1990s followed by strong cool events in the 2010s. There is little evidence of an increase in frequency of events, with 12 warm and 13 cool events in the first half of the record compared with 10 warm and 8 cool events in the second half. While on average there was about one warm or cool event every year, the events were not uniformly spaced in time, for example, there was a nearly 8 -year period (1990-1998) with no warm events and 8 cool events, and no cool events occurred after January 2014. There is a significant trend towards longer-duration MHW (slope $=7 \mathrm{~d}$ decade $^{-1}, \mathrm{r}^{2}=0.3, \mathrm{p}=0.01$ ), with the mean duration increasing from $8 \mathrm{~d}$ during the 1980 s to $26 \mathrm{~d}$ during the $2010 \mathrm{~s}$, but there was no significant change in the duration of $\operatorname{MCS}($ mean value $=12 \mathrm{~d}, \mathrm{p}=0.18)$.

Prior to about 2006, $\mathrm{SST}_{\text {TAS }}$ appears to be positively correlated with the Southern Oscillation Index (SOI) lagged by 6 months, with all but one cool event occurring when the SOI was negative and all but two warm events occurring when the SOI was near zero or positive. However, about 2006, the apparent correlation between $\mathrm{SST}_{\mathrm{TAS}}$ and SOI breaks down so that after this date the correlation appears to be negative. There is no significant correlation between the SOI and $\mathrm{SST}_{\mathrm{TAS}}$ over the whole record.

Space precludes showing all 43 events, however to illustrate the variability in their spatial structure, Figure 3 shows $\mathrm{SST}_{\mathrm{A}}$ at the peak of four representative warm and cool events (every $5^{\text {th }}$ event when sorted by $\mathrm{SST}_{\mathrm{TAS}}$ ). While there is considerable variability from event to event, the warm events often show regions in addition to the Tasman Sea where $\mathrm{SST}_{\mathrm{A}}$ exceeds 2 - in the Indian, eastern south Pacific Ocean and Atlantic Oceans. Similarly, cool events often show regions where $\mathrm{SST}_{\mathrm{A}}<-1$ off the west coast of South America, with weaker cool anomalies in the Atlantic Ocean. 
The average of $\mathrm{SST}_{\mathrm{A}}$ at the peak of all 22 warm events (Figure 4) has a maximum value in the Tasman Sea, as would be expected, where mean $\mathrm{SST}_{\mathrm{A}}>1.0$, but in addition, there regions in the Atlantic and Pacific Oceans where mean $\mathrm{SST}_{\mathrm{A}}$ exceeds 0.5, and a lessor region in the Atlantic Ocean where mean $\mathrm{SST}_{\mathrm{A}}$ exceeds 0.25 . The average air pressure anomaly, $\mathrm{P}_{\mathrm{A}}$, for all 22 warm events shows a clear W4 structure, with three strong highs (mean $\mathrm{P}_{\mathrm{A}}>5 \mathrm{hPa}$, labelled A to C) centred south-east of the respective highs in $\mathrm{SST}_{\mathrm{A}}$, and a $4^{\text {th }}$, weaker high in $\mathrm{P}_{\mathrm{A}}$ south of South Africa (D).

Mean $\mathrm{SST}_{\mathrm{A}}$ averaged over all 21 cool events is similar to the mean of warm events, but with opposite sign, so that every region of positive $\mathrm{SST}_{\mathrm{A}}$ in the mean warm event has a corresponding region of negative $\mathrm{SST}_{\mathrm{A}}$ in the mean cool event. Similarly, mean $\mathrm{P}_{\mathrm{A}}$ for the cool events shows a W4 structure, but shifted about $45^{\circ}$ in longitude compared to the mean of warm events. Three deep lows $\left(\mathrm{P}_{\mathrm{A}}<-5 \mathrm{hPa}\right.$, labelled $\mathrm{W}$ to $\mathrm{Y}$ ) occur in about the same locations as the strong highs in the mean warm event, with a shallower low (Z) south of Africa.

Figure 4 alone is fairly strong evidence that on average, MHW/MCS in the Tasman Sea co-occur with MHW/MCS in the Indian, Pacific and Atlantic Oceans, and that the likely drivers are a wavenumber 4 anomalies in air pressure. Based on this we constructed 'Canonical' MHW and MCS from averages of all 22 warm events and all 21 cool events. Figure 5 illustrates the $\mathrm{SST}_{\mathrm{A}}$ and $\mathrm{P}_{\mathrm{A}}$ progression of these canonical MHW and MCS from $45 \mathrm{~d}$ prior to the peak to the peak in $\mathrm{SST}_{\mathrm{A}}$ (the peak $\mathrm{SST}_{\mathrm{A}}$ fields are those shown in Figure 4).

In the canonical MHW, $45 \mathrm{~d}$ prior to the peak, there is little evidence of positive $\mathrm{SST}_{\mathrm{A}}$ in the Indian Ocean or Tasman Sea, although an area of positive $\mathrm{SST}_{\mathrm{A}}$ appears in the subtropics east of New Zealand (centred at $35^{\circ} \mathrm{S}, 145^{\circ} \mathrm{W}$ ). At $30 \mathrm{~d}$ before peak, this region has moved eastward, and at the same time positive $\mathrm{SST}_{\mathrm{A}}$ anomalies begin to appear in the Tasman Sea and Indian Ocean. Over the next month, these positive anomalies intensify to reach maximum intensity and size at peak event.

Forty-five days prior to the peak in canonical MHW, air pressure anomaly shows the three highs $\left(\mathrm{P}_{\mathrm{A}}>3 \mathrm{hPa}\right)$ south of Africa (A), Australia (B), and in the Atlantic Ocean (D), with a weak high ( $>2 \mathrm{hPa}$ ) west of South America (C). Over the next $45 \mathrm{~d}$, the high south of Africa (A) propagates eastwards while the Australian high 
199 (B) moves eastwards more slowly, so that an intense low develops between them. By $20015 \mathrm{~d}$ prior to the peak, the Australian high sits over and to the east of New Zealand, 201 and remains stationary until the peak, then dissipates.

202 The canonical MCS develops somewhat similarly, but with opposite sign. The 203 correspondence is not exact, the main differences being that MCS appear to develop 204 earlier than MHW with cool SST anomalies appearing around New Zealand by $45 \mathrm{~d}$ 205 prior to peak. It is also not so easy to track the progression or air pressure lows across 206 the globe. For example, the lows X and Y appear to develop from a low (XY) that 207 splits into several components, two of which intensify to become the well-developed 208 lows $\mathrm{X}$ and $\mathrm{Y}$ visible at the MCS peak.

209 The temporal development of the canonical MHW/MCS can also be illustrated 210 by Hovmöller diagrams of SST, air pressure, air-sea heat flux, and wind stress, 211 anomalies at $45^{\circ} \mathrm{S}$ (Figure 6). In the canonical MHW, SST anomalies of 0.25 begin to 212 appear about $30 \mathrm{~d}$ prior to the peak and last until about $50 \mathrm{~d}$ after the peak. Prior to 213 about $60 \mathrm{~d}$ before the peak, air pressure, heat flux, and to some extent wind stress 214 anomalies show clear evidence of eastward propagation at $\sim 4-5^{\circ} \mathrm{d}^{-1}$, with a mean 215 period of about $20 \mathrm{~d}$. Some of these coherent anomalies can be tracked across the 216 entire globe. About $50 \mathrm{~d}$ prior to the peak, however, this coherent propagation begins 217 to break down, and it appears that the highs labelled A to D stall and intensify from 218 about $40 \mathrm{~d}$ prior to peak. They then propagate eastward at slower rates of about $1-2^{\circ}$ $219 \mathrm{~d}^{-1}$.

About $20 \mathrm{~d}$ after peak, these highs dissipate, and the dominant $4-5^{\circ} \mathrm{d}^{-1}$ eastward 221 propagation returns. In a similar manner, the heat flux anomaly shows coherent $5^{\circ} \mathrm{d}^{-1}$ 222 eastward propagation until about $60 \mathrm{~d}$ prior to the peak, when anomalous negative 223 values (ocean heating) appear coincident with the air pressure highs, with the 224 strongest anomalies $\left(-20 \mathrm{~W} \mathrm{~m}^{-2}\right)$ coincident with high B. Although not shown here, 225 this signal is almost entirely due to latent heat. There is little evidence of either 226 increased or decreased wind stress during the MHW.

227 The canonical MCS is generally similar to the canonical MHW, but of opposite 228 sign. The main differences are that Tasman Sea cooling $\left(\mathrm{SST}_{\mathrm{A}}<-.25\right)$ appears much 229 earlier and it is the Indian Ocean, rather than the Atlantic Ocean pole that shows 230 weakest cooling. Coherent eastward propagation of $\mathrm{P}_{\mathrm{A}}$ appears to break down earlier 
231 than in the MHW, so that the lows $\mathrm{W}$ to $\mathrm{Z}$ are not so apparent until about $20 \mathrm{~d}$ prior to

232 the peak. There are decreased air pressure anomalies and increased heat loss

233 associated with the $\mathrm{SST}_{\mathrm{A}}$ cooling, these appear much earlier than corresponding

234 values in the MHW. There is also a suggestion of increased wind stress associated

235 with the Tasman Sea MCS.

\section{Discussion}

The main findings are that once the annual cycle and long-term trend are removed, and when normalised by the $90^{\text {th }}$ percentile, the Tasman Sea is a major region of MHW in the southern hemisphere, there is little evidence that MHW or MCS are increasing in either frequency or intensity in the Tasman Sea, and that MHW and MCS in the Tasman Sea are driven by a wavenumber 4 atmospheric forcing.

241 Removal of the annual cycle and long-term trend is predicated on the assumption that MHW or MCS are spells when the SST is significantly warmer or cooler than expected, and that the expected value changes with time. By removing the trend, we perhaps force the result that there is no increase in frequency or intensity of events. In this respect, we differ from other workers who do not remove the trend and conclude that MHW are increasing in intensity (e.g. Oliver et al., 2018).

Even if MHW are not increasing in intensity, it may still be that their biological impacts are more severe than decades ago. A full discussion of the biological impact of MHW/MCS is beyond the scope of this article, but it is worth pointing out that many taxa can tolerate only brief periods of above normal temperature. For these, the increase in MHW duration may have the most biological impact - organisms that that are killed by $10 \mathrm{~d}$ of warming might have survived 4 decades ago but would not survive today.

Normalising by the $90^{\text {th }}$ percentile is designed to account for regional variability in SST variance (e.g. Hobday et al., 2018). But this has a subtle effect in that any

256 phenomena having globally similar amplitude would be scaled down in regions where 257 other mechanisms lead to strong SST variability. This may in part explain why the 258 otherwise quiescent eastern Tasman Sea appears to be a hotspot in MHW. If this 259 effect is true, our canonical MHW/MCS could mis-represent the SST response. But 260 by not normalising the air pressure, heat flux, or wind stress anomalies, our analysis 261 presents regionally unbiased descriptions of the atmospheric forcing. There will be 
262 some error introduced by aligning events by the peak in $\mathrm{SST}_{\mathrm{TAS}}$, perhaps by several 263 days for each event, and this presumably adds some noise to the Hovmöller diagrams.

264 Similarly, we would not expect all MHW/MCS to evolve at the same rate, and

265 variations from one event to the next will also lead to noise in the Hovmöller

266 diagrams, explaining why even when they are at their most coherent it can sometimes

267 be difficult to track individual events in either the ocean response or atmospheric 268 forcing.

269 Overall, however, it is clear that the air pressure anomalies are dominated by a 270 wavenumber 4 (W4) events that propagate eastwards, and that during MHW/MCS, 271 this eastward propagation stalls for up to two months and so sets up co-occurring 272 MHW in the Indian, and eastern Pacific, and Atlantic Oceans.

273 Over the Tasman Sea, this slowdown in propagation sets up anomalous high 274 pressure south-east of New Zealand (as is often observed, e.g. Salinger et al., 2019), 275 which in turn drives anomalously north-easterly winds over the region that in the 276 canonical MHW are not much weaker than usual. These winds set up anomalous 277 southwards directed near-surface ocean currents with consequent SST rise as 278 described by Behrens et al. (2019). It has been conjectured that remote forcing by 279 Rossby waves also contributes to Tasman Sea MHW by increasing poleward transport 280 of the East Australian Current and its extension (Li et al., 2020), but it is not clear 281 how such a mechanism fits into our canonical MHW - we do not see any evidence of 282 Rossby waves in the Hovmöller diagrams for $45^{\circ} \mathrm{S}$ (Figure 6), or at any other latitude 283 south of $25^{\circ} \mathrm{S}$ (not shown).

284 The canonical MCS are driven similarly, but the W4 air pressure events stall 285 one-half wavelength zonally out of phase to the MHW events, setting up an 286 anomalous low air pressure east of New Zealand driving northward advection of 287 cooler surface water. In these events, there may also be anomalously stronger wind 288 stress, adding a vertical mixing component to the cooling.

289 The W4 structure of the atmospheric forcing appears to be a regular occurrence. 290 Senapati et al. (2021) report a stationary W4 pattern in SST set up in summer over the 291 southern hemisphere, suggesting that that the W4 pattern is set up by coupling 292 between the atmosphere and ocean. It appears that this forcing drives an ocean SST 293 response also in a W4 pattern (Fauchereau et al., 2003). 
This work suggests that the canonical MHW/MCS are manifestations of a regular austral summer set-up of W4 zonally propagating atmospheric anomalies that in some years stall out and intensify. What drives this stalling and intensification is not clear. However, it is clear that even with 40 years of data, it can be quite problematic to make inferences from correlations with atmospheric indices. Figure 2 shows a correlation with the SOI that changes sign around 2005. Had we only had the record prior to 2005, we might have concluded a positive correlation between equatorial pressure and Tasman Sea temperature anomalies, but had we only had the record post 2005, we would have come up with the opposite conclusion. As Holbrook et al. (2019) note, relationships between MHW and climate modes are complex.

\section{Methods}

\section{Daily OI SST reanalysis products (Banzon et al., 2014) from 1 September 1981} to 31 December 2020 were obtained from NOAA. At each location, the annual cycles were first removed from the daily SST, then the 1982-2020 trend was removed. Following Hobday et al. (2018) SST anomalies were then normalised by the local $90^{\text {th }}$ percentiles to produce the normalised SST anomaly, $\mathrm{SST}_{\mathrm{A}}$. Daily reanalyses of air pressure, heat fluxes and wind stress obtained from NCEP were treated similarly (annual cycles and trend removed), but not normalised to produce anomalies, $\mathrm{P}_{\mathrm{A}}, \mathrm{Q}_{\mathrm{A}}$, and $\tau_{A}$, respectively.

The Tasman Box has been defined by previous workers as the region between $46^{\circ} \mathrm{S}$ and $28^{\circ} \mathrm{S}$ and between $147^{\circ} \mathrm{E}$ and $173^{\circ} \mathrm{E}$ (Behrens et al., 2019). The mean temperature in the Tasman Box (weighted for grid area), $\mathrm{SST}_{\mathrm{TAS}}$, was computed as is shown in Figure 2. Warm and cool events were then defined when SST $_{\text {TAS }}$ exceeded 1 or was less than -1 , respectively for at least 5 days. Events were required to be separated by at least 90 days.

The 22 warm and 21 cool events thus identified were then averaged to form canonical MHW and MCS, by aligning each event in time centred on the respective peak values of $\mathrm{SST}_{\mathrm{TAS}}$, thus computing an evolving mean event extending two months either side of the peak. Corresponding timeseries of air pressure, air-sea heat flux, and wind stress anomalies were computed using the same alignments. 
Hovmöller diagrams of $\mathrm{SST}_{\mathrm{A}}, \mathrm{P}_{\mathrm{A}}, \mathrm{Q}_{\mathrm{A}}$, and $\tau_{A}$ for $45^{\circ} \mathrm{S}$ were computed by

324 averaging the respective quantities over a $5^{\circ}$ latitude band and plotting against

325 longitude.

326 The significance of the slope of linear regressions was calculated following

327 Santer et al. (2000).

\section{Data Availability}

328 Only publicly available data were used in this research, and no new data were

329 generated. NOAA $1 / 4^{\circ}$ daily Optimum Interpolation Sea Surface Temperature

330 (OISST) are available from https://www.ncdc.noaa.gov/oisst. NCEP daily reanalyses

331 of air pressure, heat fluxes and wind stress were obtained from

332 http://www.esrl.noaa.gov/psd/data/gridded/data.ncep.reanalysis.surfaceflux.html.

333 The Southern Oscillation Index (SOI) was obtained from the Australian Bureau

334 of Meteorology (BoM) website http://www.bom.gov.au/climate/enso/soi/.

\section{Acknowledgements}

335 We thank NOAA, NCEP, and BoM for making the respective reanalysis products

336 freely available. This work was supported by the New Zealand Ministry of Business,

337 Innovation and Employment through grants to NIWA's Climate, and Coasts and

338 Oceans programmes and their predecessors. 


\section{References}

Bâki Iz, H. (2018). Is the global sea surface temperature rise accelerating? Geodesy and Geodynamics, 9(6), 432-438. doi:10.1016/j.geog.2018.04.002

Banzon, V. F., Reynolds, R. W., Stokes, D., \& Xue, Y. (2014). A 1/4º-SpatialResolution Daily Sea Surface Temperature Climatology Based on a Blended Satellite and in situ Analysis. Journal of Climate, 27(21), 8221-8228. doi:10.1175/jcli-d-14-00293.1

Behrens, E., Fernandez, D., \& Sutton, P. (2019). Meridional Oceanic Heat Transport Influences Marine Heatwaves in the Tasman Sea on Interannual to Decadal Timescales. Frontiers in Marine Science, 6. doi:10.3389/fmars.2019.00228

Bond, N. A., Cronin, M. F., Freeland, H., \& Mantua, N. (2015). Causes and impacts of the 2014 warm anomaly in the NE Pacific. Geophysical Research Letters, 42(9), 3414-3420. doi:10.1002/2015GL063306

Bulgin, C. E., Merchant, C. J., \& Ferreira, D. (2020). Tendencies, variability and persistence of sea surface temperature anomalies. Scientific Reports, 10(1), 7986. doi:10.1038/s41598-020-64785-9

Chiswell, S. M., \& O'Callaghan, J. M. (2021). Long-term trends in the frequency and magnitude of upwelling along the West Coast of the South Island, New Zealand, and the impact on primary production. New Zealand Journal of Marine and Freshwater Research, 1-22. doi:10.1080/00288330.2020.1865416

Fauchereau, N., Trzaska, S., Richard, Y., Roucou, P., \& Camberlin, P. (2003). Seasurface temperature co-variability in the Southern Atlantic and Indian Oceans and its connections with the atmospheric circulation in the Southern Hemisphere. International Journal of Climatology, 23(6), 663-677. doi:https://doi.org/10.1002/joc.905

Gordon, A. L. (1989). Brazil-Malvinas Confluence-1984. Deep Sea Research Part A. Oceanographic Research Papers, 36(3), 359-384. doi:10.1016/01980149(89)90042-3

Hobday, A., Oliver, E., Sen Gupta, A., Benthuysen, J., Burrows, M., Donat, M., et al. (2018). Categorizing and Naming Marine Heatwaves. Oceanography, 31(2). doi:10.5670/oceanog.2018.205

Holbrook, N. J., Scannell, H. A., Sen Gupta, A., Benthuysen, J. A., Feng, M., Oliver, E. C. J., et al. (2019). A global assessment of marine heatwaves and their 
drivers. Nature Communications, 10(1), 2624. doi:10.1038/s41467-01910206-Z

Hulburt, P. (2018). Salmon industry in short supply turns to Atlantic seas for help The Marlborough Express

Jones, T., Parrish, J. K., Peterson, W. T., Bjorkstedt, E. P., Bond, N. A., Ballance, L. T., et al. (2018). Massive Mortality of a Planktivorous Seabird in Response to a Marine Heatwave. Geophysical Research Letters, 45(7), 3193-3202. doi:https://doi.org/10.1002/2017GL076164

Li, Z., Holbrook, N. J., Zhang, X., Oliver, E. C. J., \& Cougnon, E. A. (2020). Remote Forcing of Tasman Sea Marine Heatwaves. Journal of Climate, 33(12), 53375354. doi:10.1175/JCLI-D-19-0641.1

Lutjeharms, J. R. E., \& Van Ballegooyen, R. C. (1988). The Retroflection of the Agulhas Current. Journal of Physical Oceanography, 18(11), 1570-1583. doi:10.1175/1520-0485(1988)018<1570:Trotac $>2.0$. Co;2

Oliver, E. C. J., Benthuysen, J. A., Bindoff, N. L., Hobday, A. J., Holbrook, N. J., Mundy, C. N., et al. (2017). The unprecedented 2015/16 Tasman Sea marine heatwave. Nature Communications, 8, 16101. doi:10.1038/ncomms16101

Oliver, E. C. J., Benthuysen, J. A., Darmaraki, S., Donat, M. G., Hobday, A. J., Holbrook, N. J., et al. (2021). Marine Heatwaves. Ann Rev Mar Sci, 13, 313342. doi:10.1146/annurev-marine-032720-095144

Oliver, E. C. J., Donat, M. G., Burrows, M. T., Moore, P. J., Smale, D. A., Alexander, L. V., et al. (2018). Longer and more frequent marine heatwaves over the past century. Nature Communications, 9(1), 1324. doi:10.1038/s41467-018-037329

Roemmich, D., Gould, W. J., \& Gilson, J. (2012). 135 years of global ocean warming between the Challenger expedition and the Argo Programme. Nature Climate Change, 2(6), 425-428. doi:Doi 10.1038/Nclimate1461

Salinger, M. J., Renwick, J., Behrens, E., Mullan, A. B., Diamond, H. J., Sirguey, P., et al. (2019). The unprecedented coupled ocean-atmosphere summer heatwave in the New Zealand region 2017/18: drivers, mechanisms and impacts. Environmental Research Letters, 14(4). doi:10.1088/1748-9326/ab012a

Santer, B. D., Wigley, T. M. L., Boyle, J. S., Gaffen, D. J., Hnilo, J. J., Nychka, D., et al. (2000). Statistical significance of trends and trend differences in layeraverage atmospheric temperature time series. Journal of Geophysical 
405

406

407

408

409

410

411

412

413

414

415

416

417

418

419

420

421

422

423

Research: Atmospheres, 105(D6), 7337-7356. doi:10.1029/1999jd901105

Schaeffer, A., \& Roughan, M. (2017). Subsurface intensification of marine heatwaves off southeastern Australia: The role of stratification and local winds.

Geophysical Research Letters, 44(10), 5025-5033.

doi:10.1002/2017GL073714

Sen Gupta, A., Thomsen, M., Benthuysen, J. A., Hobday, A. J., Oliver, E., Alexander, L. V., et al. (2020). Drivers and impacts of the most extreme marine heatwaves events. Scientific Reports, 10(1), 19359. doi:10.1038/s41598-020$75445-3$

Senapati, B., Dash, M. K., \& Behera, S. K. (2021). Global wave number-4 pattern in the southern subtropical sea surface temperature. Scientific Reports, 11(1), 142. doi:10.1038/s41598-020-80492-X

Sutton, P. J. H., \& Bowen, M. (2019). Ocean temperature change around New Zealand over the last 36 years. New Zealand Journal of Marine and Freshwater Research, 1-22. doi:10.1080/00288330.2018.1562945

Wernberg, T., Bennett, S., Babcock, R. C., de Bettignies, T., Cure, K., Depczynski, M., et al. (2016). Climate-driven regime shift of a temperate marine ecosystem. Science, 353(6295), 169-172. doi:10.1126/science.aad8745 


\section{Figures}

Figure 1. a) 1982-2020 trend in sea surface temperature, SST, computed from the Reynolds OISST reanalysis; b) $90^{\text {th }}$ percentile in SST anomalies once the trend and annual cycles are removed; c) Number of days between 1982 and 2020 where the SST anomaly exceeded 3 times the $90^{\text {th }}$ percentile. Black lines show the 'Tasman Box' used to compute the temperature index, SST TAS.

Figure 2. Mean SST anomaly, $\mathrm{SST}_{\mathrm{TAS}}$ (i.e. with trend and annual cycle removed, and normalised by the $90^{\text {th }}$ percentile) computed over the Tasman Box shown in Figure 1. Circles show peaks of warm and cool 'events' when $\mathrm{SST}_{\text {TAS }}$ was greater than 1 or less than -1 for at least 5 d. Filled circles indicate the events shown in Figure 3. Also shown is the Southern Oscilation Index (SOI) smoothed with a 6-month window, divided by 2 and plotted with a 6-month lag.

Figure 3. Left-hand panel shows representiative warm events (defined when Tasman Sea mean normalised SST anomaly, $\mathrm{SST}_{\mathrm{TAS}}$, was greater than 1, see Figure 2). Right-hand panels show representative cool events (Tasman Sea mean $\mathrm{SST}_{\mathrm{TAS}}<-1$ ). The upper panels (23 December 2017 and 1 January 2007) show the strongest warm and cool events, respectively.

Figure 4. a) Mean normalised sea surface temperature anomaly, $\mathrm{SST}_{\mathrm{A}}$, of all 22 warm events (indicated by red circles in Figure 2) and mean air pressure anomaly, $\mathrm{P}_{\mathrm{A}}$, for the same events; b) Mean $\mathrm{SST}_{\mathrm{A}}$ and $\mathrm{P}_{\mathrm{A}}$ for all 21 cool events (indicated by blue circles in Figure 2). A to $\mathrm{D}$ and $\mathrm{X}$ to $\mathrm{Z}$ indicate highs and lows discussed in the text.

Figure 5. Progression of canonical MHW and MCS (see text). a) Canonical MHW showing sea surface temperature anomaly, $\mathrm{SST}_{\mathrm{A}}$, and air pressure anomaly, $\mathrm{P}_{\mathrm{A}}$, from $45 \mathrm{~d}$ prior to peak event in Tasman Sea, to $20 \mathrm{~d}$ after peak event. A to $\mathrm{D}$ indicate highs discussed in the text; b) Corresponding values for canonical MCS. XY and $\mathrm{X}$ to $\mathrm{Z}$ indicate lows discussed in the text. 
457 Figure 6. Hovmöller diagrams for canonical MHW and MCS at $45^{\circ} \mathrm{S}$ showing normalised SST anomaly, $\mathrm{SST}_{\mathrm{A}}$, air pressure anomaly, $\mathrm{P}_{\mathrm{A}}$, air-sea heat flux anomaly, $\mathrm{Q}_{\mathrm{A}}$, and wind stress anomaly $\tau_{\mathrm{A}}$. The peak event occurs at time $=0$ d. Labels $A$ to $D$ and $X$ to $Z$ indicate lows shown in Figure 4 and Figure 5. Vertical dashed lines show the longitude of New Zealand at this latitude +/$90^{\circ},+180^{\circ}$. Blank areas in $\mathrm{SST}_{\mathrm{A}}$ indicate the land masses of Asutralia, New Zealand, and South America. Sloped solid and longer dashed lines indicate a phase-speed of $5^{\circ} \mathrm{d}^{-1}$. Shorter dashed lines indicate slower speeds ascribed to highs ( $\mathrm{A}$ to $\mathrm{D}$ ) and lows ( $\mathrm{W}$ to $\mathrm{Z}$ ) in $\mathrm{P}_{\mathrm{A}}$. The heat convention is that negative values indicate heat entering the ocean. 


\section{Figures}

a)

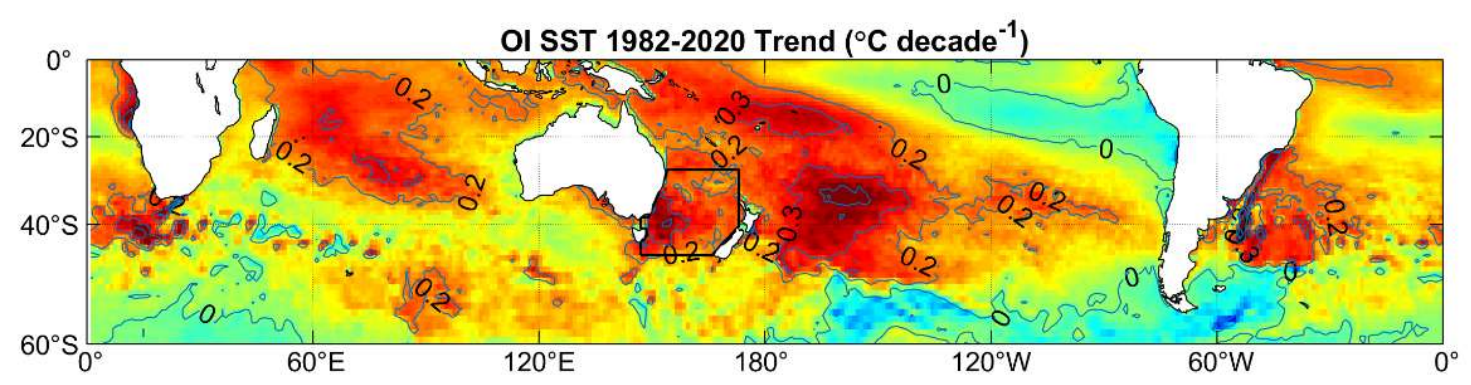

b)

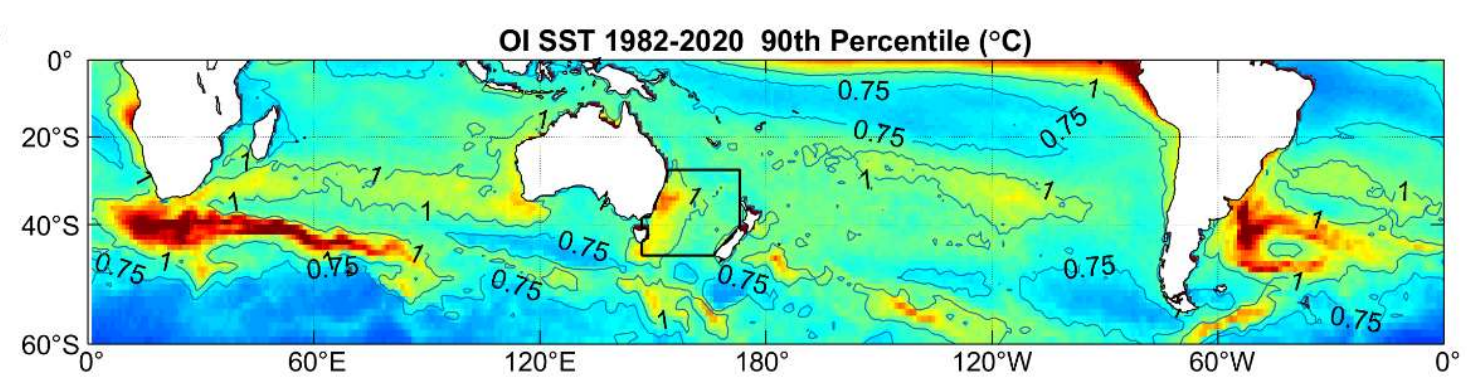

c)

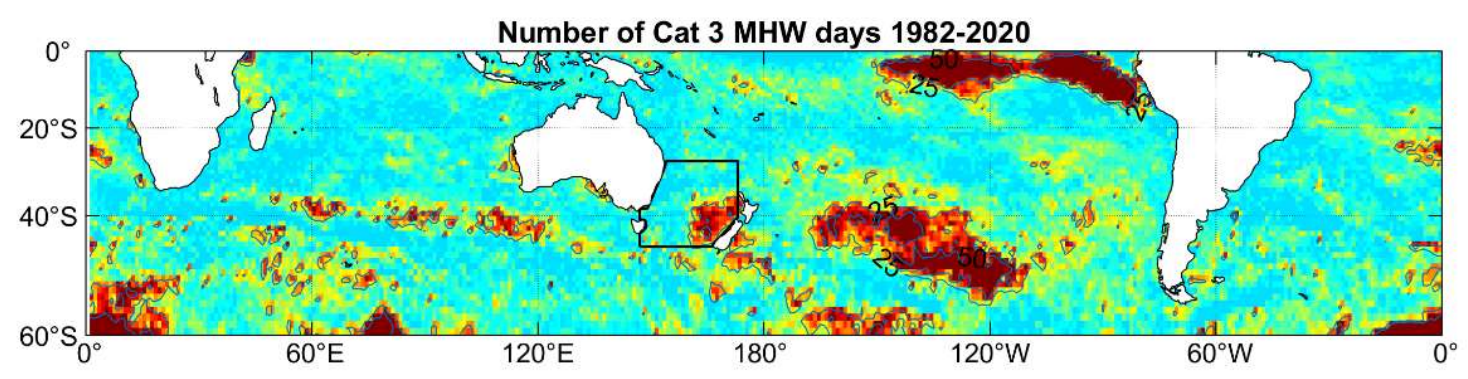

Figure 1. a) 1982-2020 trend in sea surface temperature, SST, computed from the Reynolds OISST reanalysis; b) 90th percentile in SST anomalies once the trend and annual cycles are removed; c) Number of days between 1982 and 2020 where the SST anomaly exceeded 3 times the 90th percentile. Black lines show the 'Tasman Box' used to compute the temperature index, SSTTAS. 


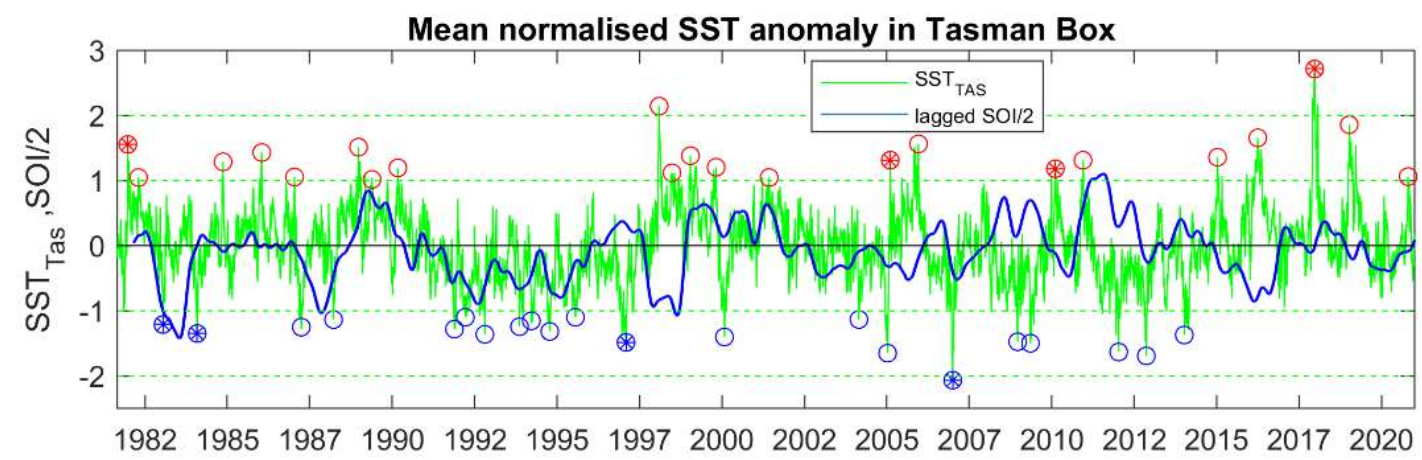

Figure 2. Mean SST anomaly, SSTTAS (i.e. with trend and annual cycle removed, and normalised by the 90th percentile) computed over the Tasman Box shown in Figure 1. Circles show peaks of warm and cool 'events' when SSTTAS was greater than 1 or less than -1 for at least $5 \mathrm{~d}$. Filled circles indicate the events shown in Figure 3. Also shown is the Southern Oscilation Index (SOI) smoothed with a 6-month window, divided by 2 and plotted with a 6-month lag. 

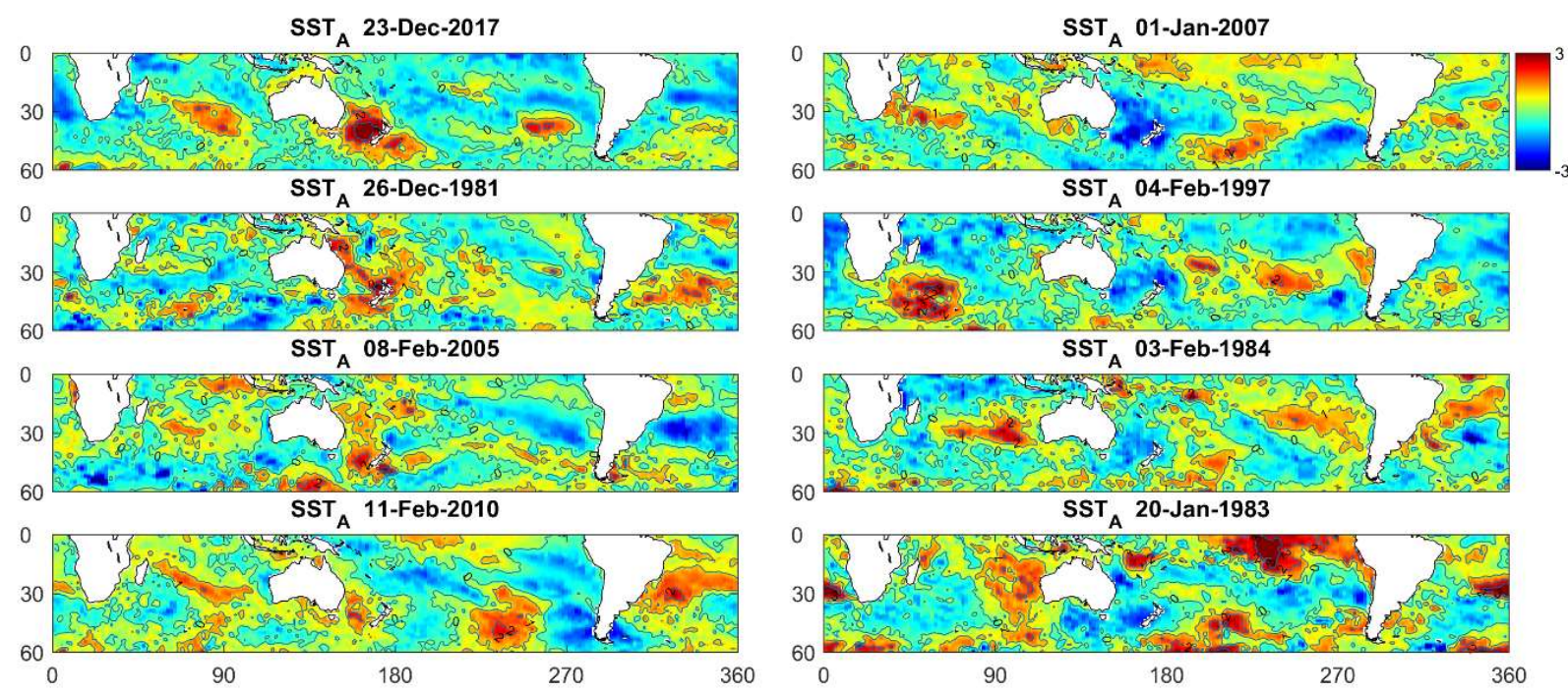

483 Figure 3. Left-hand panel shows representiative warm events (defined when Tasman Sea mean normalised SST anomaly, SSTTAS, was greater than 1, see Figure 2). Right-hand panels show representative cool events (Tasman Sea mean SSTTAS <-1). The upper panels (23 December 2017 and 1 January 2007) show the strongest warm and cool events, respectively. 


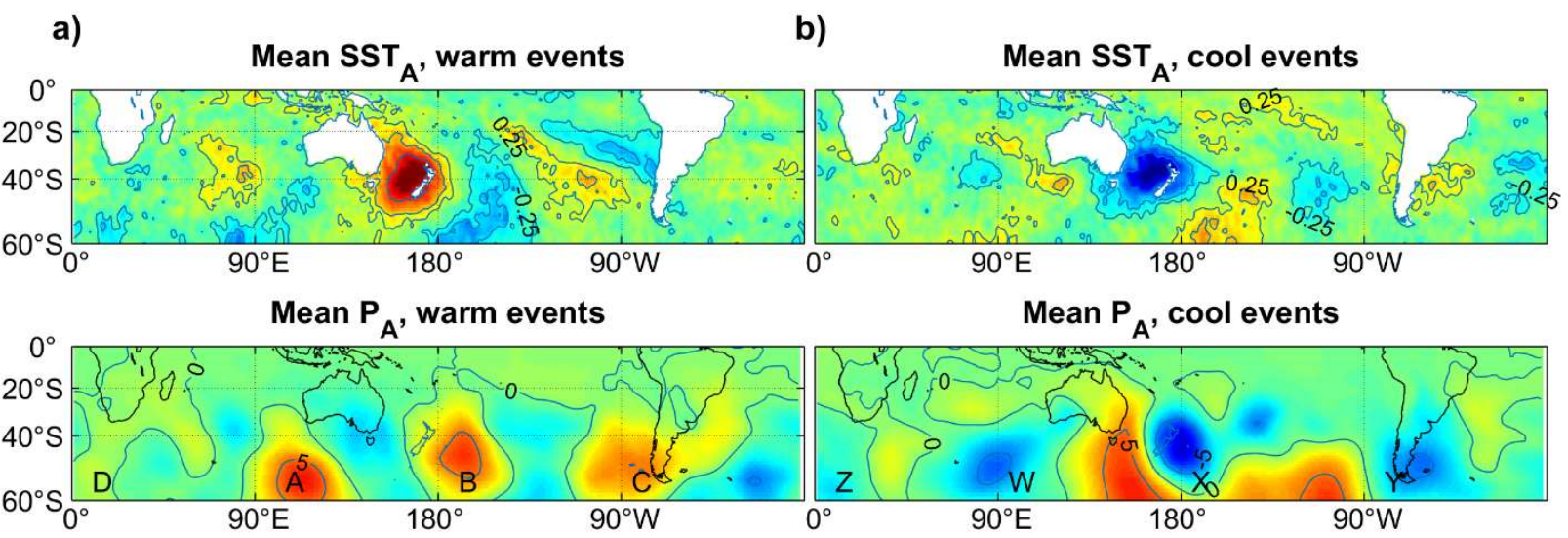

489 Figure 4. a) Mean normalised sea surface temperature anomaly, SSTA, of all 22 warm events (indicated by red circles in Figure 2) and mean air pressure anomaly, PA, for the same events; b) Mean SSTA and PA for all 21 cool events (indicated by blue circles in Figure 2). A to D and $\mathrm{X}$ to $\mathrm{Z}$ indicate highs and lows discussed in the text. 
a) Canonical Marine Heat Wave
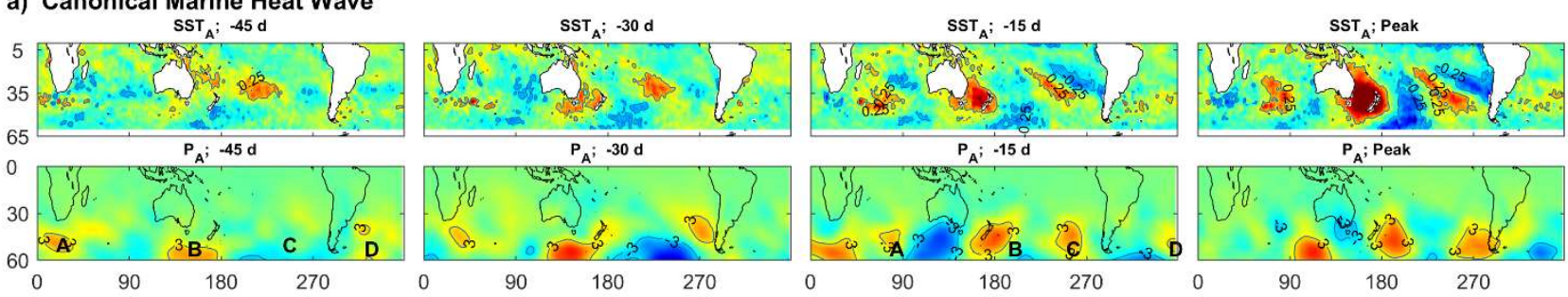

b) Canonical Marine Cold Spell
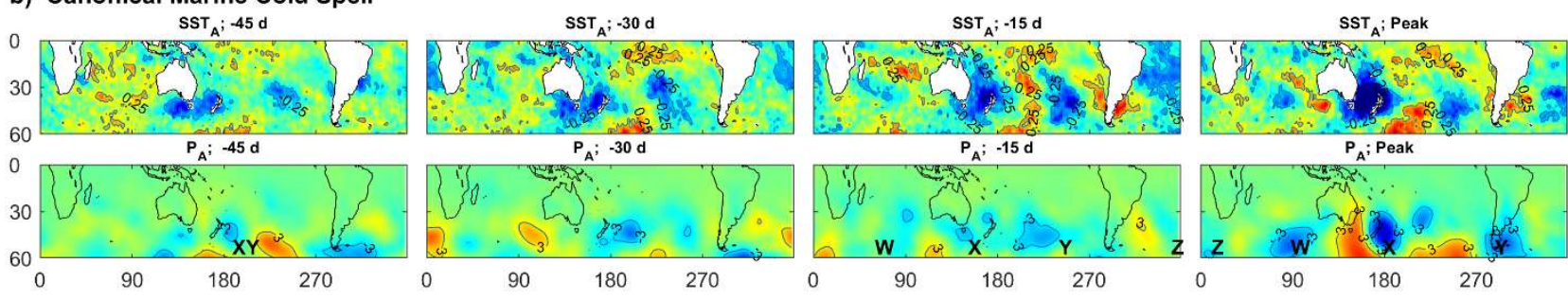

Figure 5. Progression of canonical MHW and MCS (see text). a) Canonical MHW showing sea surface temperature anomaly, SSTA, and air pressure anomaly, PA, from $45 \mathrm{~d}$ prior to peak event in Tasman Sea, to $20 \mathrm{~d}$ after peak event. A to $\mathrm{D}$ indicate highs discussed in the text; b) Corresponding values for canonical MCS. XY and X to $\mathrm{Z}$ indicate lows discussed in the text. 


\section{a) Canonical MHW}

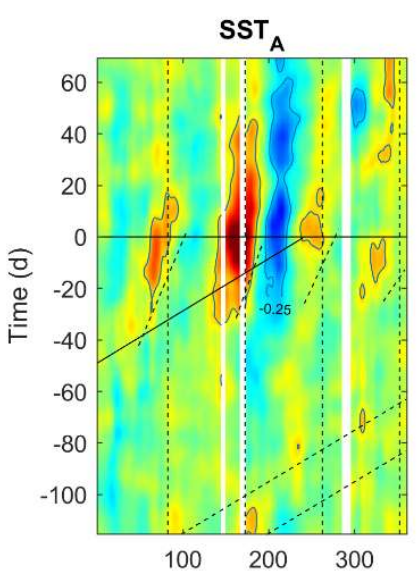

b) Canonical MCS

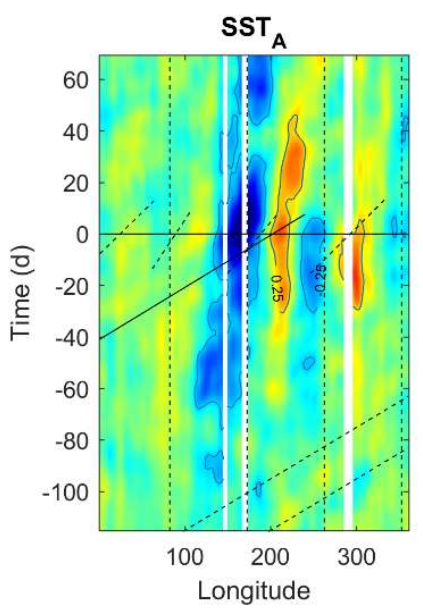

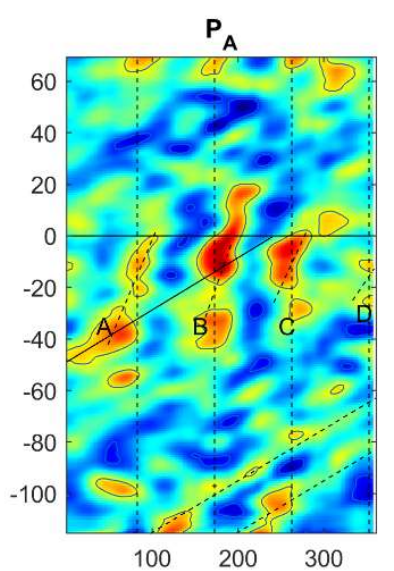
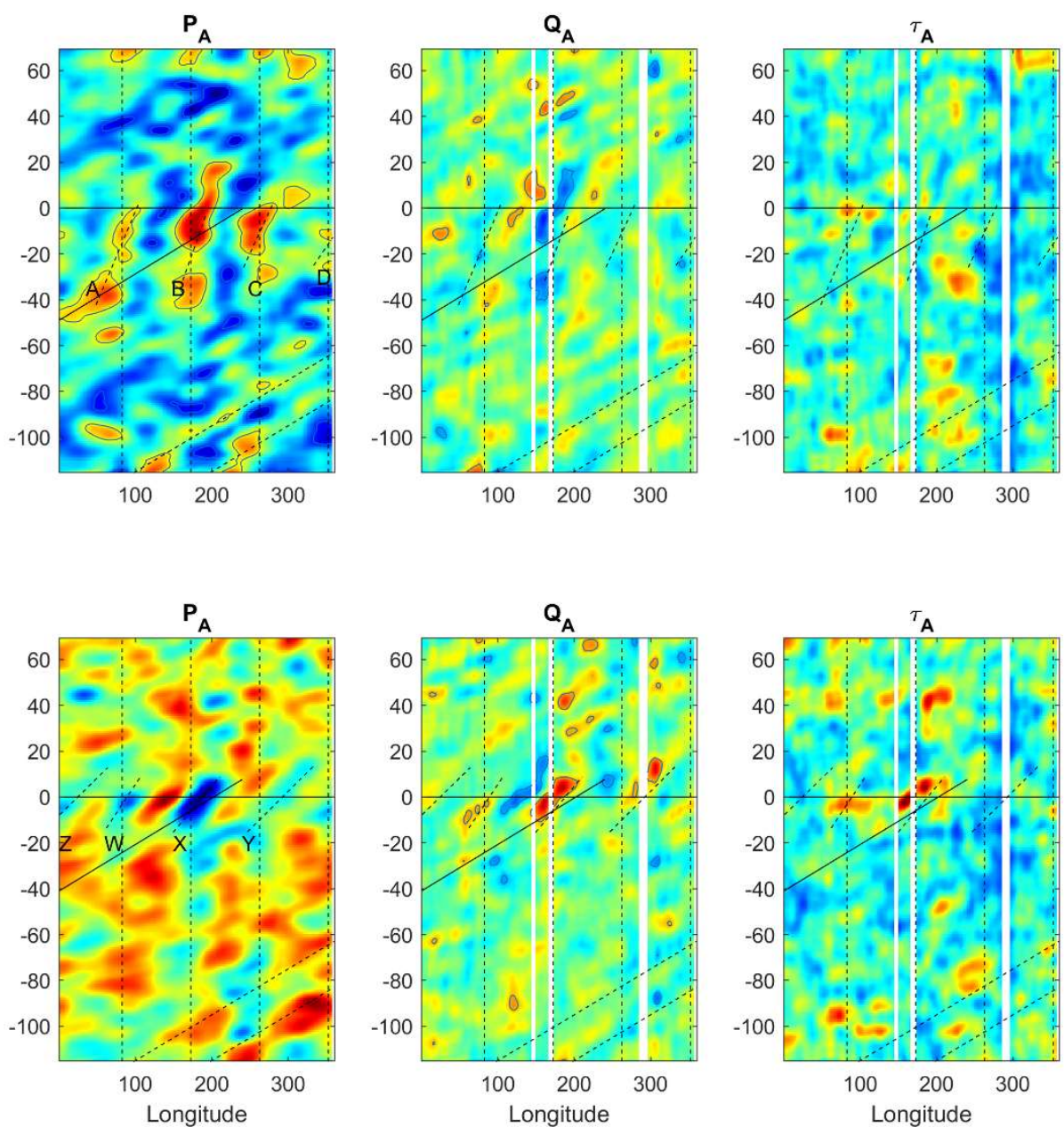

Figure 6. Hovmöller diagrams for canonical MHW and MCS at $45^{\circ} \mathrm{S}$ showing normalised SST anomaly, SSTA, air pressure anomaly, PA, air-sea heat flux anomaly, QA, and wind stress anomaly $\tau$ A. The peak event occurs at time $=0$ d. Labels $A$ to $D$ and $X$ to $Z$ indicate lows shown in Figure 4 and Figure 5. Vertical dashed lines show the longitude of New Zealand at this latitude +/$90^{\circ},+180^{\circ}$. Blank areas in SSTA indicate the land masses of Asutralia, New Zealand, and South America. Sloped solid and longer dashed lines indicate a phase-speed of $5^{\circ} \mathrm{d}-1$. Shorter dashed lines indicate slower speeds ascribed to highs (A to D) and lows (W to Z) in PA. The heat convention is that negative values indicate heat entering the ocean. 
a)

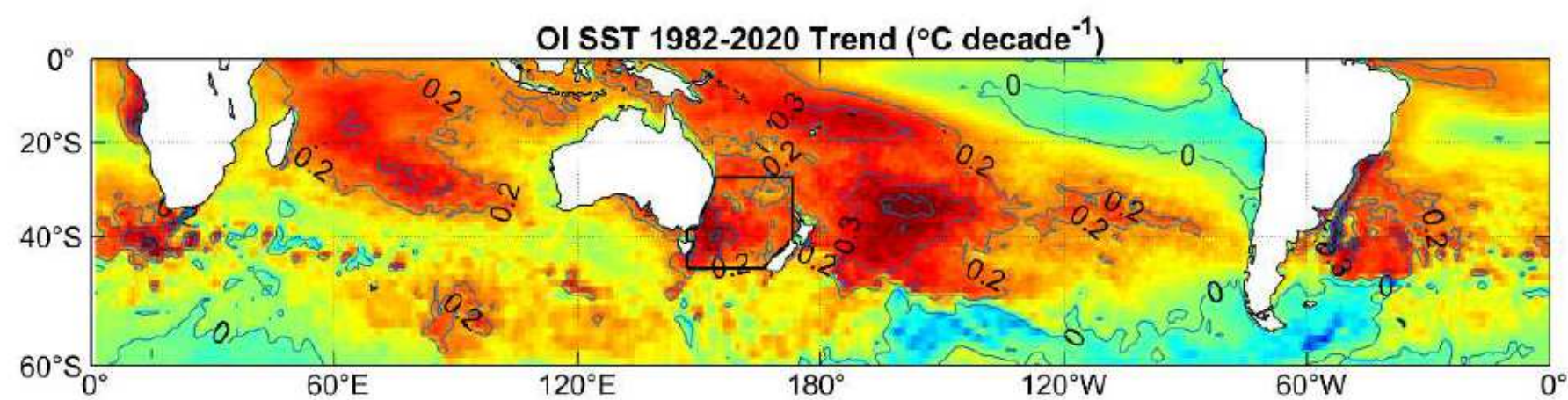

b)

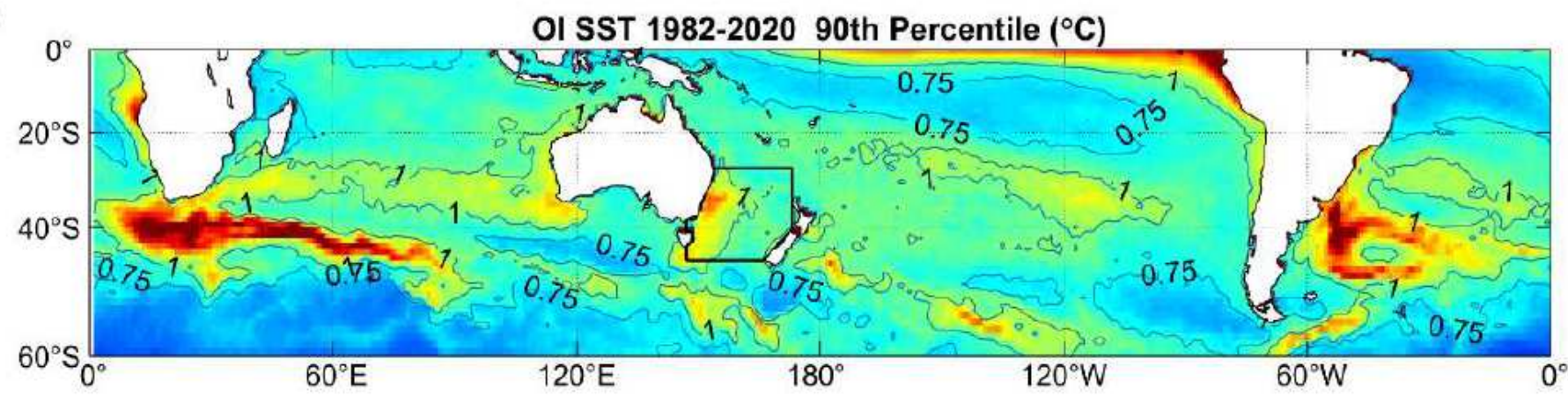

c)

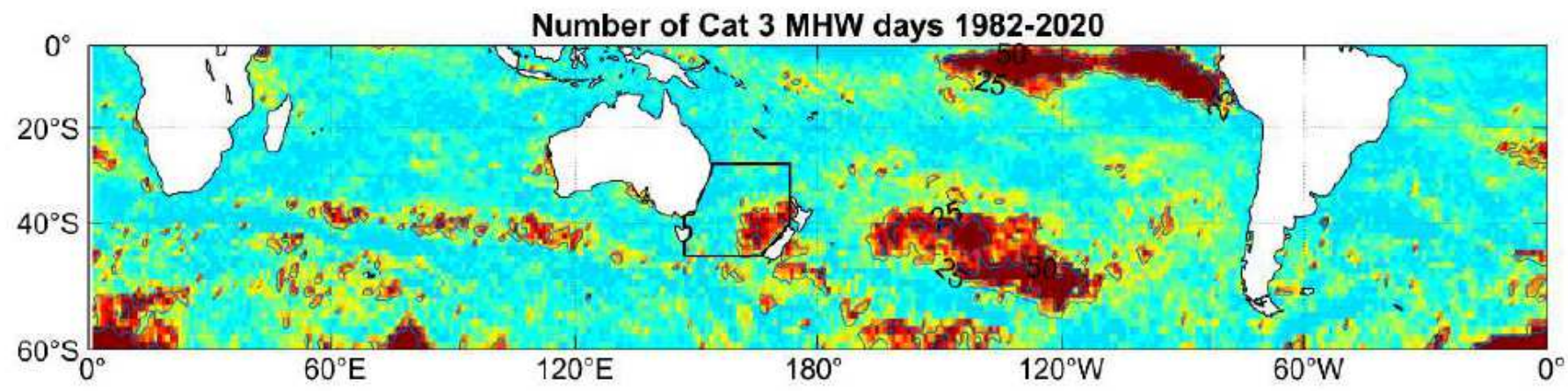

Figure 1

a) 1982-2020 trend in sea surface temperature, SST, computed from the Reynolds OISST reanalysis; b) 90th percentile in SST anomalies once the trend and annual cycles are removed; c) Number of days between 1982 and 2020 where the SST anomaly exceeded 3 times the 90th percentile. Black lines show the 'Tasman Box' used to compute the temperature index, SSTTAS. Note: The designations employed and the presentation of the material on this map do not imply the expression of any opinion whatsoever on the part of Research Square concerning the legal status of any country, territory, city or area or of its authorities, or concerning the delimitation of its frontiers or boundaries. This map has been provided by the authors. 


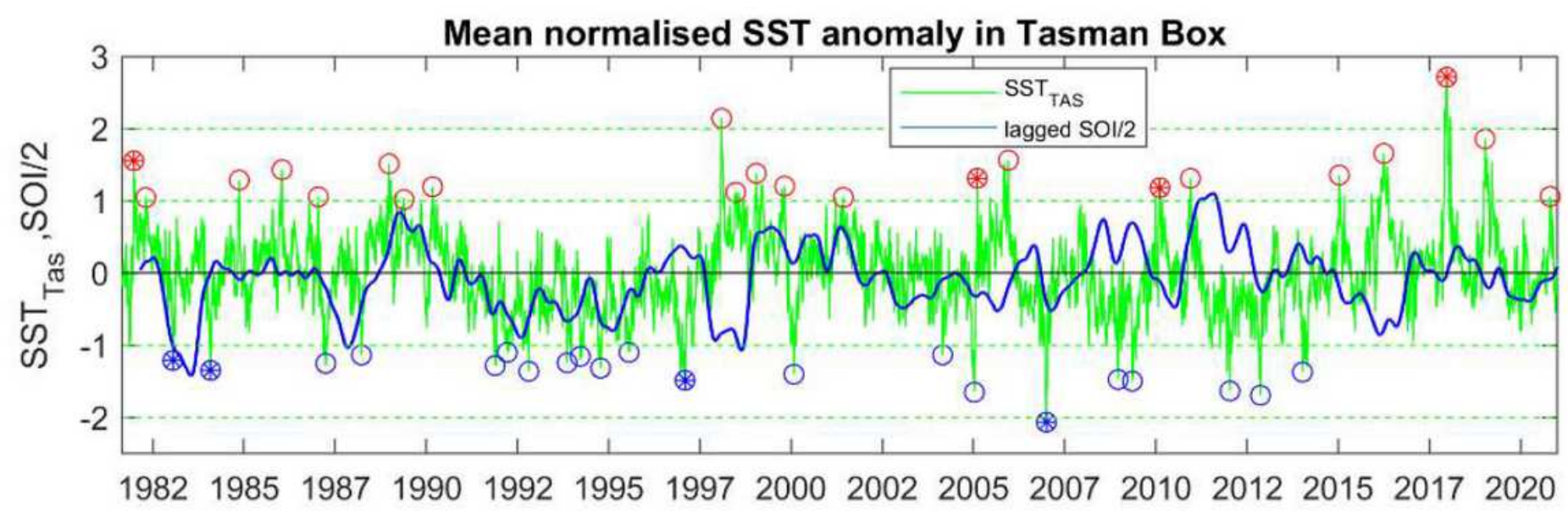

\section{Figure 2}

Mean SST anomaly, SSTTAS (i.e. with trend and annual cycle removed, and normalised by the 90th percentile) computed over the Tasman Box shown in Figure 1. Circles show peaks of warm and cool 'events' when SSTTAS was greater than 1 or less than -1 for at least $5 \mathrm{~d}$. Filled circles indicate the events shown in Figure 3. Also shown is the Southern Oscilation Index (SOI) smoothed with a 6-month window, divided by 2 and plotted with a 6-month lag.
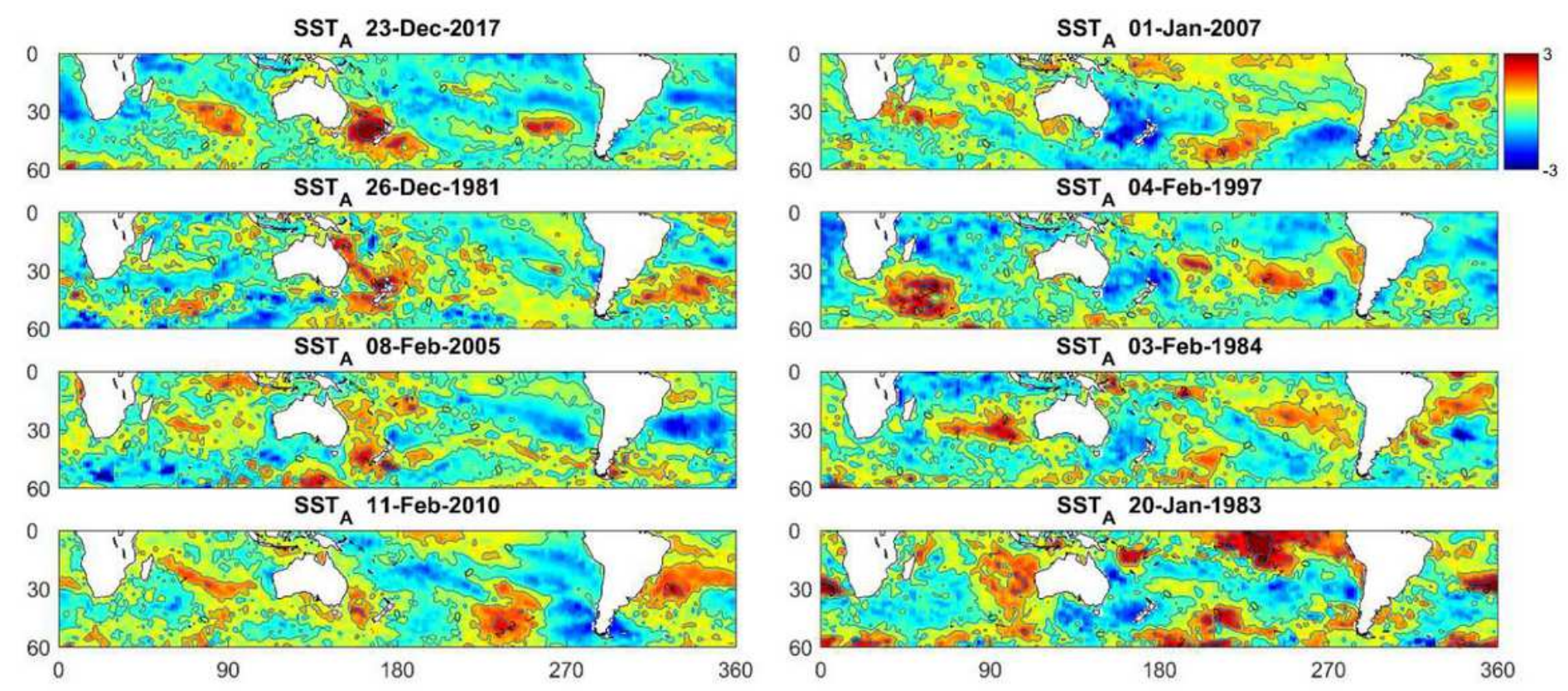

Figure 3

Left-hand panel shows representiative warm events (defined when Tasman Sea mean normalised SST anomaly, SSTTAS, was greater than 1, see Figure 2). Right-hand panels show representative cool events (Tasman Sea mean SSTTAS <-1). The upper panels (23 December 2017 and 1 January 2007) show the strongest warm and cool events, respectively. Note: The designations employed and the presentation of 
the material on this map do not imply the expression of any opinion whatsoever on the part of Research Square concerning the legal status of any country, territory, city or area or of its authorities, or concerning the delimitation of its frontiers or boundaries. This map has been provided by the authors.

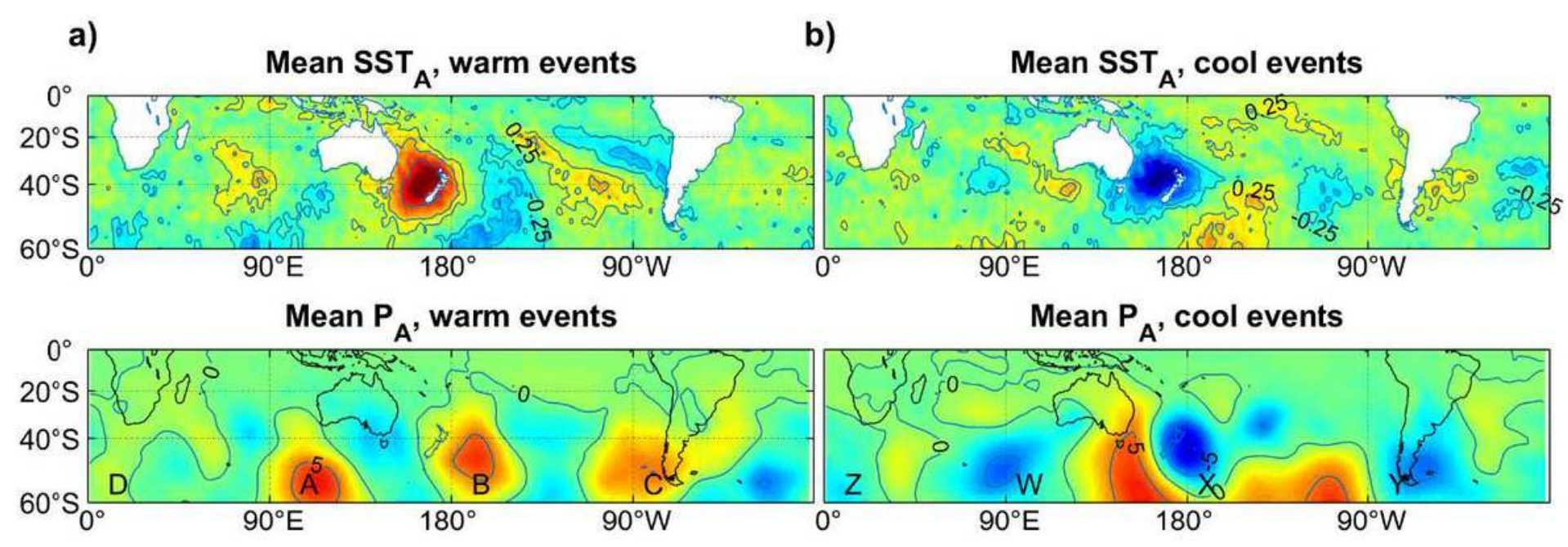

Figure 4

a) Mean normalised sea surface temperature anomaly, SSTA, of all 22 warm events (indicated by red circles in Figure 2) and mean air pressure anomaly, PA, for the same events; b) Mean SSTA and PA for all $21 \mathrm{cool}$ events (indicated by blue circles in Figure 2). A to $D$ and $X$ to $Z$ indicate highs and lows discussed in the text. Note: The designations employed and the presentation of the material on this map do not imply the expression of any opinion whatsoever on the part of Research Square concerning the legal status of any country, territory, city or area or of its authorities, or concerning the delimitation of its frontiers or boundaries. This map has been provided by the authors.
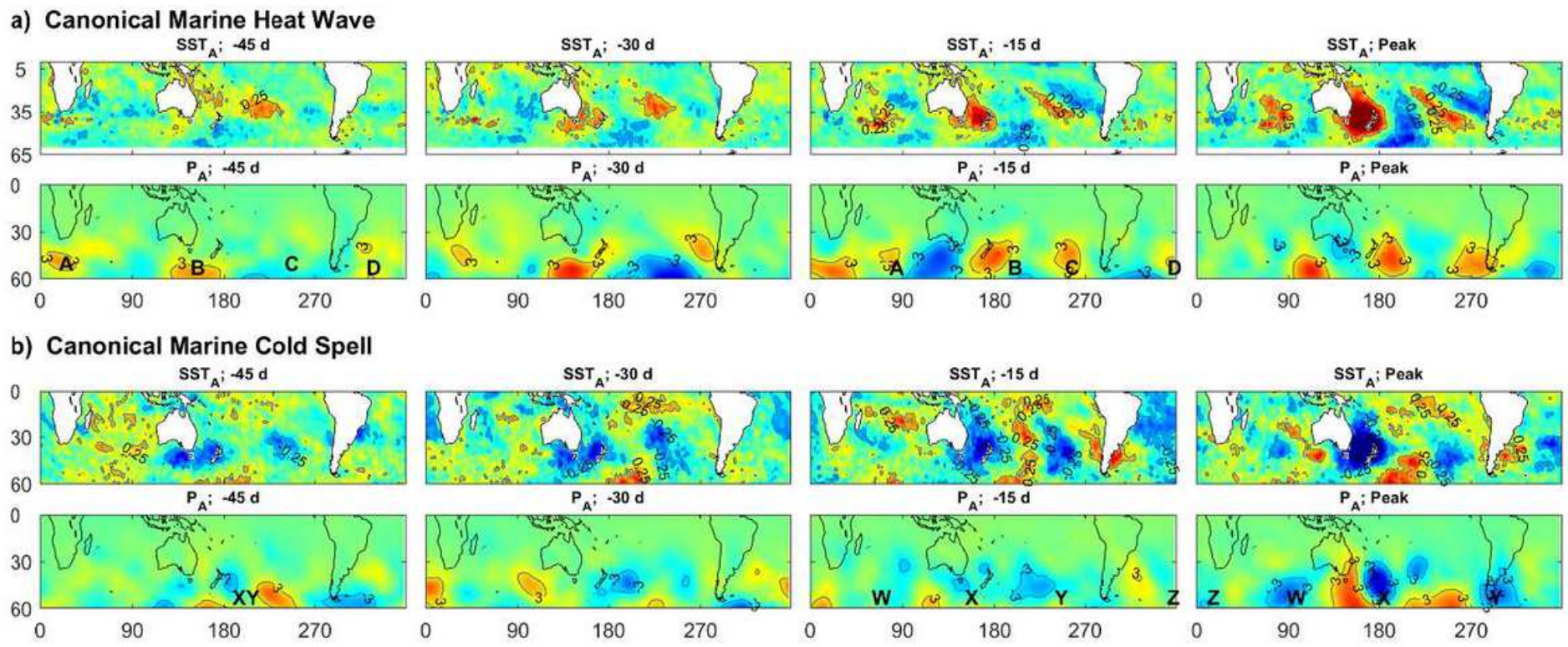

Figure 5 
Progression of canonical MHW and MCS (see text). a) Canonical MHW showing sea surface temperature anomaly, SSTA, and air pressure anomaly, PA, from $45 \mathrm{~d}$ prior to peak event in Tasman Sea, to $20 \mathrm{~d}$ after peak event. $A$ to $D$ indicate highs discussed in the text; $b$ ) Corresponding values for canonical MCS. XY and $X$ to $Z$ indicate lows discussed in the text. Note: The designations employed and the presentation of the material on this map do not imply the expression of any opinion whatsoever on the part of Research Square concerning the legal status of any country, territory, city or area or of its authorities, or concerning the delimitation of its frontiers or boundaries. This map has been provided by the authors.

a) Canonical MHW

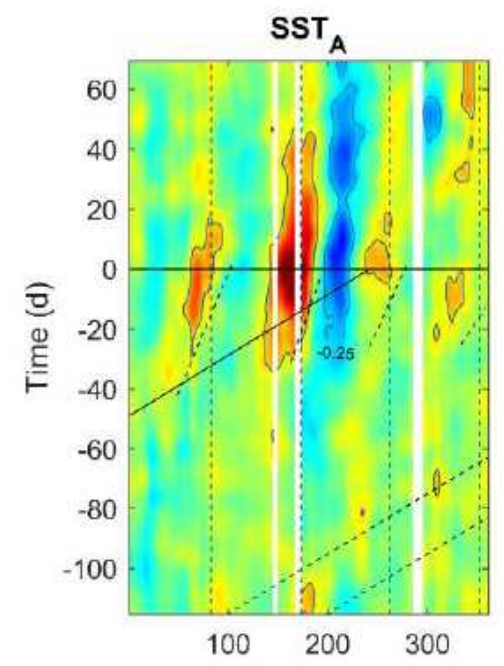

b) Canonical MCS

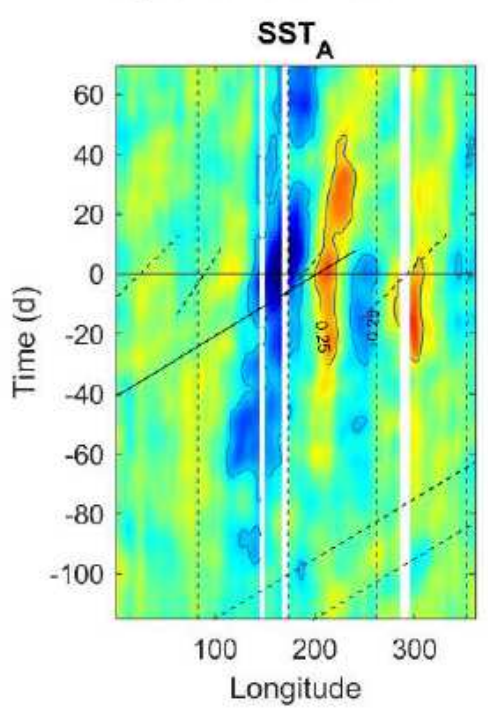

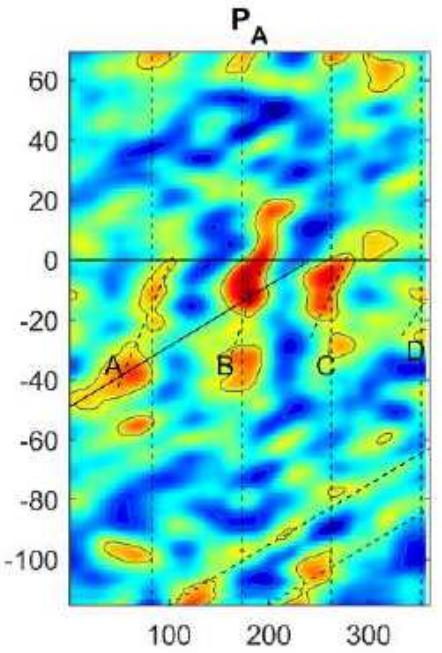

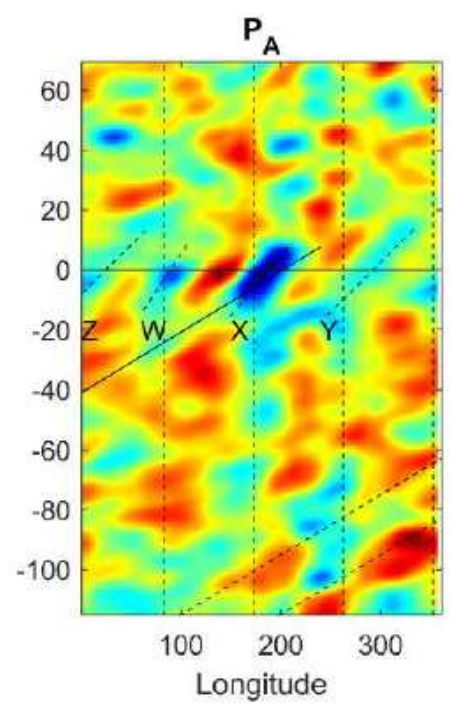

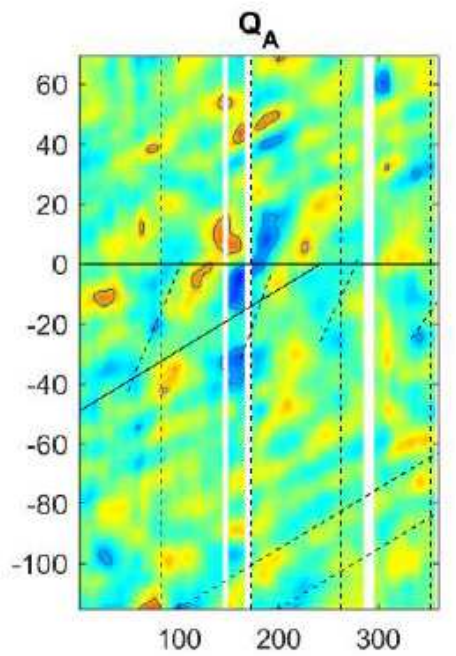
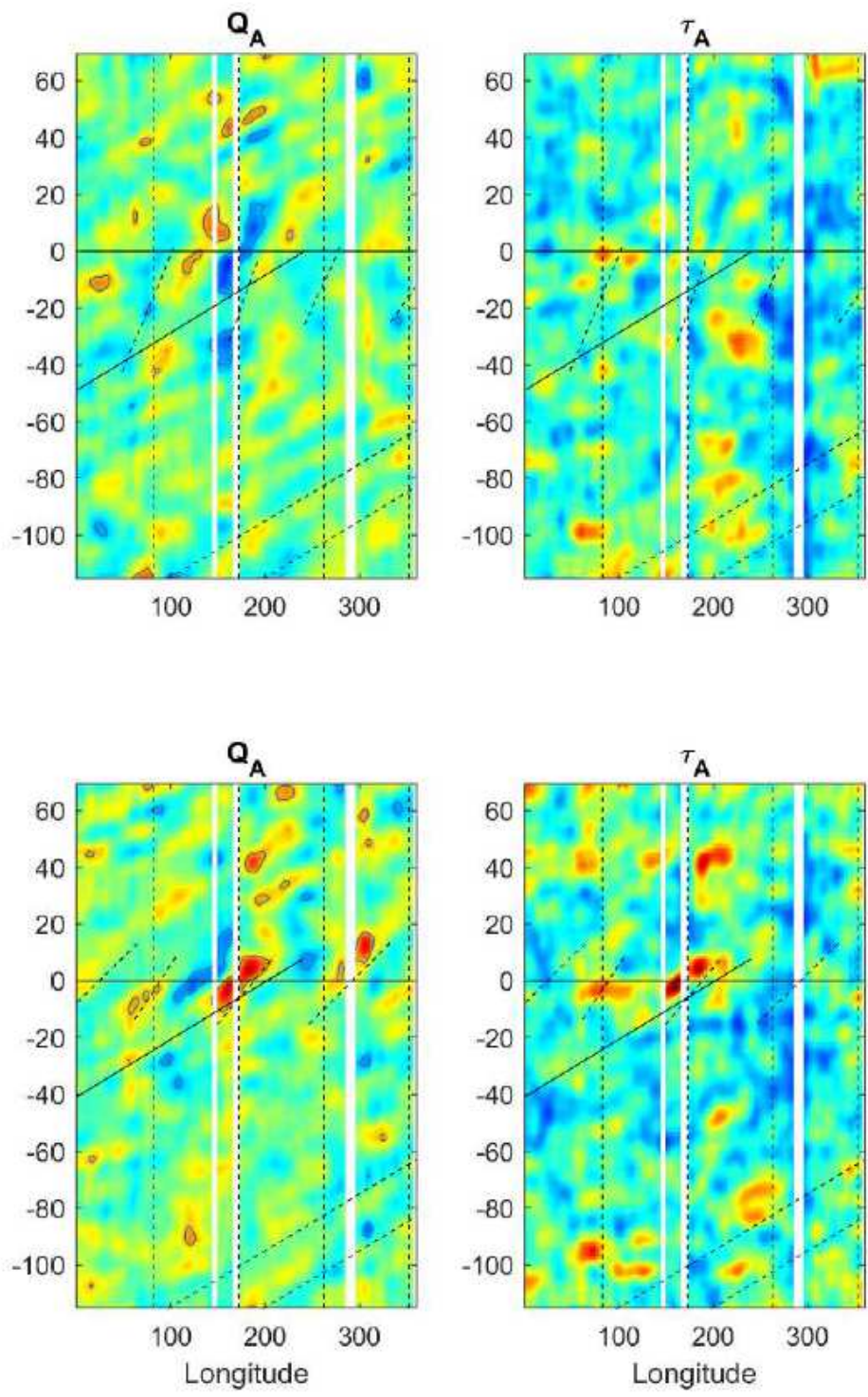

\section{Figure 6}

Hovmöller diagrams for canonical MHW and MCS at $45^{\circ} \mathrm{S}$ showing normalised SST anomaly, SSTA, air pressure anomaly, PA, air-sea heat flux anomaly, QA, and wind stress anomaly $\tau$. The peak event occurs at time $=0 \mathrm{~d}$. Labels $A$ to $D$ and $X$ to $Z$ indicate lows shown in Figure 4 and Figure 5. Vertical dashed lines show the longitude of New Zealand at this latitude $+/-90^{\circ},+180^{\circ}$. Blank areas in SSTA indicate the land masses of Asutralia, New Zealand, and South America. Sloped solid and longer dashed lines indicate a 
phase-speed of $5^{\circ} \mathrm{d}-1$. Shorter dashed lines indicate slower speeds ascribed to highs (A to $D$ ) and lows ( $W$ to $Z$ ) in PA. The heat convention is that negative values indicate heat entering the ocean. 